\title{
Modeling of cytotoxicity on some non- nucleoside reverse transcriptase inhibitors of HIV-1: role of physicochemical parameters
}

\author{
B.K. Tiwari, ${ }^{a}$ A. Thakur, ${ }^{\text {* }}$ M. Thakur, ${ }^{c}$ N. D. Pandey, ${ }^{a}$ S. S. Narvi, ${ }^{a}$ and S. Thakurd \\ ${ }^{a}$ Department of Chemistry, M.N.N.I.T., Allahabad, India \\ ${ }^{b}$ Department of Chemistry, Rishiraj institute of Technology, Indore, India \\ ${ }^{c}$ Department of Chemistry, Softvision institute of Bio-Technology, Indore, India \\ Department of Physics, S.V.I.T.S., Indore, India \\ E-mail: Abhilashthakur@yahoo.com
}

(received 6 Aug 05; accepted 18 Jan 06; published on the web 3 Feb 06)

\begin{abstract}
In present study efforts have been made to develop a mathematical model for a set of 18 1-[(2hydroxyethoxy)-methyl]-6-(phenylthio)thymine (HEPT) Derivatives. The biological activity modeled in present investigation is cytotoxic concentration $(\log 1 / \mathrm{C})$. To investigate the cytotoxic behavior of HEPT derivatives, classical and non- conventional physicochemical properties are tested separately. On the basis of the results obtained we model the compound having maximum predictive potential.
\end{abstract}

Keywords: Cytotoxic concentration, QSAR, multiple linear regression

\section{Introduction}

Quantitative structure - activity relationship and quantitative property-activity relationship (QSAR/QPAR) studies are unquestionably of great importance in modern chemistry and biochemistry. The concept of quantitative structure - activity relationship and quantitative structure - property relationship (QSAR/QSPR) is to mutate searches for compounds with desired properties using chemical intuitions and experiences into quantified and computerized form. Once a correlation between structure and activity/ property is found, any number of compounds, including those not yet synthesized, can be easily screened on computer in sequence to select structures with the desired potential and properties. Thus, the quantitative structureactivity relationships and quantitative property-activity relationship approach accelerates the process of development for new molecules. ${ }^{1}$

Quantitative structure activity (QSAR) represents an attempt to correlate structural or molecular descriptors of compound with activities. These physicochemical descriptors, which 
include parameters to accounts for hydrophobicity, topology, electronic parameters and steric effects, are determined empirically or more recently by computational methods. Quantitative structure activity relationship (QSAR) is currently being applied in many disciplines, with many pertaining to drug design and environmental risk assessments. ${ }^{2}$

In the recent past there was considerable interest in the set-up of quantitative structureactivity relationships (QSAR) of HEPT derivatives. ${ }^{3-10}$ These HEPT derivatives belongs to the class of NNRTIs (Non- nucleotide reverse transcriptase inhibitors) which inhibits the HIV-1 reverse transcriptase, one of the most attractive target for drug therapy. This enzyme (HIV-1 RT) is essential for HIV replication and it is not binding for normal host cell replication. HIV-1 reverse transcriptase copies the RNA genome into DNA for HIV. The NNRTIs shows the specific inhibition against the HIV-1 with low cytotoxicity and few, side effects. ${ }^{11-14}$

In continuation of our earlier studies ${ }^{15-23}$ and inspired by the recent work ${ }^{24-29}$ We have undertaken the present study in that we have made QSAR analysis on the Cytotoxic concentration of HEPT derivatives using a set of molecular descriptors consisting of some molecular descriptors along with the indicator parameters. We have used earlier data ${ }^{30}$ for this purpose. The classical physicochemical descriptors used being molar refractivity (MR), molar volume (MV), parachor (Pc), refractive index ( $\eta$ ), surface tension (ST), density (D) and polarizability $(\alpha)$ in addition to non-conventional parameters approximate surface area (ASA), surface area grid (SAG) and HE (hydration energy). For the QSAR modeling we have used maximum $\mathrm{R}^{2}$ method $^{31}$ and followed the stepwise regression analysis model using molecular modeling.

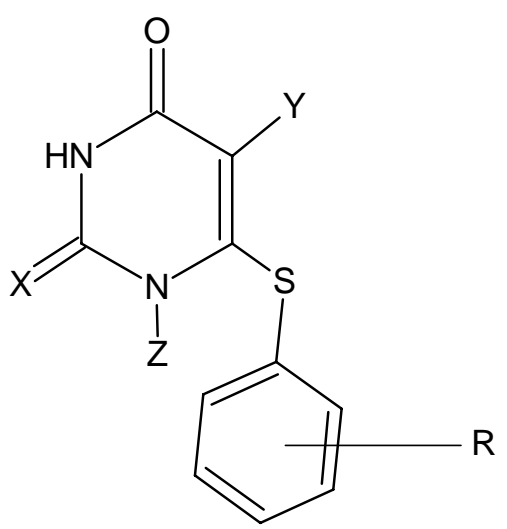

Figure 1. Parent structure of HEPT derivatives.

\section{Results and Discussion}

HEPT derivatives along with their biological activity are presented in Table 1. The classical physicochemical parameters are shown in Table 2 while non-conventional physicochemical parameters along with the indicator parameters are recorded in Table 3. The inter correlation of 
classical and non-conventional physicochemical parameters are presented in Tables 4 and 5 respectively in the form of correlation matrix. From the perusal of Table 4 mutual correlations exist between the classical physicochemical parameters MR, MV, Pc and Pol, and these parameters also correlate well with the biological activity. Models obtained from univariate correlation are shown below:

$\log 1 / \mathrm{C}=0.0284( \pm 0.0047) \mathrm{MR}+1.4393$

$\mathrm{n}=18, \mathrm{Se}=0.301, \mathrm{R}=0.692, \mathrm{R}^{2}=0.478, \mathrm{~F}=14.672, \mathrm{Q}=2.3$

$\log 1 / \mathrm{C}=0.0101( \pm 0.0028) \mathrm{MV}+1.4351$

$\mathrm{n}=18, \mathrm{Se}=0.309, \mathrm{R}=0.670, \mathrm{R}^{2}=0.449, \mathrm{~F}=13.043, \mathrm{Q}=2.17$

$\log 1 / \mathrm{C}=0.0036( \pm 0.0010) \mathrm{Pc}+1.4774$

$\mathrm{n}=18, \mathrm{Se}=0.311, \mathrm{R}=0.664, \mathrm{R}^{2}=0.441, \mathrm{~F}=12.616, \mathrm{Q}=2.13$

All the three equations show the significant role of classical physicochemical parameters in the modeling of $\log 1 / \mathrm{C}$. Comparison of above three equations exhibits the dominance of MR over the MV and Pc, but all three parameters demonstrate the positive effect in the enhancement of biological activity $1 / \log \mathrm{C}$.

Table 1. Substituents and observed biological activity $(\log 1 / C)$ of HEPT derivatives used in the present study

\begin{tabular}{llllll}
\hline Comp.No & $\mathrm{R}$ & $\mathrm{Y}$ & $\mathrm{X}$ & $\mathrm{Z}$ & Obs. log $1 / \mathrm{C}$ \\
\hline 1. & $\mathrm{H}$ & $\mathrm{Me}$ & $\mathrm{O}$ & $\mathrm{CH}_{2} \mathrm{OCH}_{2} \mathrm{CH}_{2} \mathrm{OMe}$ & 3.25 \\
2. & $\mathrm{H}$ & $\mathrm{Me}$ & $\mathrm{O}$ & $\mathrm{CH}_{2} \mathrm{OMe}_{2}$ & 3.61 \\
3. & $\mathrm{H}$ & $\mathrm{Me}$ & $\mathrm{O}$ & $\mathrm{CH}_{2} \mathrm{OC}_{2} \mathrm{H}_{5}$ & 3.64 \\
4. & $\mathrm{H}$ & $\mathrm{Me}$ & $\mathrm{O}$ & $\mathrm{CH}_{2} \mathrm{OC}_{3} \mathrm{H}_{7}$ & 3.83 \\
5. & $\mathrm{H}$ & $\mathrm{Me}$ & $\mathrm{O}$ & $\mathrm{CH}_{2} \mathrm{OC}_{4} \mathrm{H}_{9}$ & 4.08 \\
6. & $\mathrm{H}$ & $\mathrm{Me}$ & $\mathrm{O}$ & $\mathrm{CH}_{2} \mathrm{OCH}_{2} \mathrm{C}_{6} \mathrm{H}_{5}$ & 4.02 \\
7. & $\mathrm{H}$ & $\mathrm{C}_{2} \mathrm{H}_{5}$ & $\mathrm{~S}$ & $\mathrm{CH}_{2} \mathrm{OC}_{2} \mathrm{H}_{5}$ & 4.09 \\
8. & $3,5-d i-\mathrm{Cl}$ & $\mathrm{C}_{2} \mathrm{H}_{5}$ & $\mathrm{~S}$ & $\mathrm{CH}_{2} \mathrm{OC}_{2} \mathrm{H}_{5}$ & 4.35 \\
9. & $\mathrm{H}$ & $\mathrm{Cy}-\mathrm{C}_{3} \mathrm{H}_{5}$ & $\mathrm{~S}$ & $\mathrm{CH}_{2} \mathrm{OC}_{2} \mathrm{H}_{5}$ & 4.34 \\
10. & $\mathrm{H}$ & $\mathrm{C}_{2} \mathrm{H}_{5}$ & $\mathrm{O}$ & $\mathrm{CH}_{2} \mathrm{OC}_{2} \mathrm{H}_{5}$ & 3.79 \\
11. & $\mathrm{H}$ & $\mathrm{C}_{2} \mathrm{H}_{5}$ & $\mathrm{O}$ & $\mathrm{CH}_{2} \mathrm{OCHM}_{2}$ & 3.85 \\
12. & $\mathrm{H}$ & $\mathrm{C}_{2} \mathrm{H}_{5}$ & $\mathrm{O}$ & $\mathrm{CH}_{2} \mathrm{OCH}_{2} \mathrm{C}_{6} \mathrm{H}_{11}$ & 4.77 \\
13. & $\mathrm{H}$ & $\mathrm{C}_{2} \mathrm{H}_{5}$ & $\mathrm{O}$ & $\mathrm{CH}_{2} \mathrm{OCH}_{2} \mathrm{CH}_{2} \mathrm{C}_{6} \mathrm{H}_{5}$ & 4.42 \\
14. & $\mathrm{H}$ & $\mathrm{CHMe} 2$ & $\mathrm{O}$ & $\mathrm{CH}_{2} \mathrm{OC}_{2} \mathrm{H}_{5}$ & 3.98 \\
15. & $\mathrm{H}$ & $\mathrm{Cy}-\mathrm{C}_{3} \mathrm{H}_{5}$ & $\mathrm{O}$ & $\mathrm{CH}_{2} \mathrm{OC}_{2} \mathrm{H}_{5}$ & 3.65 \\
16. & $\mathrm{H}$ & $\mathrm{Me}$ & $\mathrm{O}$ & $\mathrm{C}_{2} \mathrm{H}_{5}$ & 4.03 \\
17. & $\mathrm{H}$ & $\mathrm{Me}$ & $\mathrm{O}$ & $\mathrm{C}_{4} \mathrm{H}_{9}$ & 4.05 \\
18. & $\mathrm{H}$ & $M e$ & $\mathrm{O}$ & $\mathrm{CH}_{2} \mathrm{OCH}_{2} \mathrm{CH}_{2} \mathrm{OH}$ & 3.13 \\
\hline
\end{tabular}


Table 2. Physicochemical properties* of subset of HEPT derivatives used in the present study for calculation of $\log 1 / \mathrm{C}$

\begin{tabular}{llllllll}
\hline Comp.No. & MR & MV & Pc & $\eta$ & ST & D & $\alpha$ \\
\hline 1 & & & & & & & \\
2 & 85.10 & 246.4 & 672.9 & 1.606 & 55.5 & 1.30 & 33.73 \\
3 & 74.09 & 207.8 & 572.4 & 1.631 & 57.5 & 1.33 & 29.37 \\
4 & 78.72 & 224.0 & 612.4 & 1.620 & 55.8 & 1.30 & 31.21 \\
5 & 83.35 & 240.3 & 652.5 & 1.610 & 54.3 & 1.27 & 33.04 \\
6 & 87.98 & 256.5 & 692.6 & 1.601 & 53.1 & 1.24 & 34.88 \\
7 & 98.81 & 266.9 & 746.2 & 1.662 & 61.0 & 1.32 & 39.17 \\
8 & 90.35 & 248.4 & 694.0 & 1.647 & 60.8 & 1.29 & 35.81 \\
9 & 100.01 & 270.2 & 768.3 & 1.661 & 65.3 & 1.44 & 39.64 \\
10 & 92.92 & 246.5 & 702.6 & 1.677 & 65.9 & 1.35 & 36.83 \\
11 & 83.35 & 240.3 & 652.5 & 1.610 & 54.3 & 1.27 & 33.04 \\
12 & 87.96 & 257.1 & 690.5 & 1.599 & 52.0 & 1.24 & 34.87 \\
13 & 104.45 & 303.1 & 821.4 & 1.605 & 53.9 & 1.23 & 41.40 \\
14 & 108.07 & 299.3 & 826.4 & 1.641 & 58.1 & 1.27 & 42.84 \\
15 & 87.96 & 257.1 & 690.5 & 1.599 & 52.0 & 1.24 & 34.87 \\
16 & 85.92 & 238.3 & 661.1 & 1.640 & 59.1 & 1.33 & 34.06 \\
17 & 72.35 & 201.6 & 552.0 & 1.636 & 56.1 & 1.30 & 28.68 \\
18 & 81.61 & 234.2 & 632.2 & 1.613 & 53.0 & 1.23 & 32.35 \\
\hline
\end{tabular}

* MR = Molar Refractivity: MV = Molar Volume: Pc $=$ Parachor: $\eta=$ Index of Refraction:

ST = Surface Tension: D = Density: $\alpha=$ Polarizability

In the case of non-conventional physicochemical parameters only Hydration Energy (HE) shows the significant statistics and all those correlation resulting in low values of $\mathrm{R}(<0.50)$ are not considered being statistically insignificant. The model obtained from univariate correlation between $\mathrm{HE}$ and $\log 1 / \mathrm{C}$ is shown below,

$\log 1 / \mathrm{C}=0.1174( \pm 0.0388) \mathrm{HE}+4.5796$

$\mathrm{n}=18, \mathrm{Se}=0.314, \mathrm{R}=0.603, \mathrm{R}^{2}=0.364, \mathrm{~F}=9.163, \mathrm{Q}=1.92$

Eq. (4) exhibits the enhancement in the numerical value of cytotoxic concentration with the increase in the hydration energy. After the comparison between earlier three equations and the $4^{\text {th }}$ one, we found that classical physicochemical parameters correlate well with the activity. The comparison also exhibits the dominance of molar refraction over the other classical physicochemical parameters and non-conventional physicochemical parameters. 
Table 3. Non-conventional physicochemical parameters and Indicator parameter used in the present study for calculation of $\log 1 / \mathrm{C}$

\begin{tabular}{lllllllll}
\hline Comp No. & HE & ASA & SAG & $\mathrm{I}_{2}$ & $\mathrm{I}_{\mathrm{TC}}$ & $\mathrm{I}_{\mathrm{AC}}$ & $\mathrm{I}_{\mathrm{SP}}$ & $\mathrm{I}_{\mathrm{OH}}$ \\
\hline 1 & -7.17 & 538.40 & 560.84 & 0 & 0 & 0 & 0 & 0 \\
2 & -5.82 & 428.57 & 473.97 & 0 & 0 & 0 & 0 & 0 \\
3 & -5.09 & 463.25 & 506.07 & 0 & 0 & 0 & 0 & 0 \\
4 & -4.56 & 502.51 & 535.50 & 0 & 0 & 0 & 0 & 0 \\
5 & -4.09 & 545.38 & 570.64 & 0 & 0 & 0 & 0 & 0 \\
6 & -6.45 & 439.05 & 534.37 & 0 & 1 & 1 & 0 & 0 \\
7 & -4.69 & 480.90 & 529.86 & 1 & 0 & 0 & 0 & 0 \\
8 & -4.07 & 553.56 & 575.79 & 1 & 0 & 0 & 1 & 0 \\
9 & -4.66 & 459.13 & 542.52 & 1 & 0 & 1 & 0 & 0 \\
10 & -4.81 & 419.07 & 484.34 & 0 & 0 & 0 & 0 & 0 \\
11 & -4.41 & 449.70 & 511.84 & 0 & 0 & 0 & 0 & 0 \\
12 & -3.85 & 471.36 & 580.66 & 0 & 1 & 1 & 0 & 0 \\
13 & -6.4 & 470.68 & 587.69 & 0 & 1 & 1 & 0 & 0 \\
14 & -4.17 & 428.37 & 506.29 & 0 & 0 & 0 & 0 & 0 \\
15 & -4.07 & 404.51 & 509.61 & 0 & 0 & 1 & 0 & 0 \\
16 & -5.3 & 361.06 & 435.23 & 0 & 0 & 0 & 0 & 0 \\
17 & -4.28 & 428.37 & 486.40 & 0 & 0 & 0 & 0 & 0 \\
18 & -12.21 & 428.86 & 484.55 & 0 & 0 & 0 & 0 & 1 \\
\hline
\end{tabular}

$* \mathrm{HE}=$ Hydration Energy. ASA = Approximate Surface Area. SAG $=$ Surface Area Grid. $\mathrm{I}_{2}=1$ if the $\mathrm{S}$ atom is present at $\mathrm{X}$ position, 0 otherwise. $\mathrm{I}_{\mathrm{TC}}=1$ if the Cyclic structure is present at the terminus of the chain at the $\mathrm{Z}$ position, 0 otherwise. $\mathrm{I}_{\mathrm{AC}}=1$ if the Cyclic structure is present at the alternate atoms, 0 otherwise. $I_{S P}=1$ if the substitution is present on a Phenyl ring ( $R$ position), 0 otherwise. $\mathrm{I}_{\mathrm{OH}}=1$ if $\mathrm{OH}$ is present in the chain at the $\mathrm{Z}$ position, 0 otherwise

Table 4. Correlation matrix between biological activity and classical physicochemical parameters

\begin{tabular}{lllllllll} 
& $\log 1 / \mathrm{C}$ & MR & MV & Pc & $\eta$ & ST & D & $\alpha$ \\
\hline $\log 1 / \mathrm{C}$ & 1.00000 & & & & & & & \\
MR & 0.69162 & 1.00000 & & & & & & \\
MV & 0.67015 & 0.95867 & 1.00000 & & & & & \\
Pc & 0.66399 & 0.99129 & 0.98306 & 1.00000 & & & & \\
$\eta$ & 0.16448 & 0.25145 & -0.03358 & 0.13911 & 1.00000 & & & \\
ST & -0.00991 & 0.22503 & -0.03706 & 0.14608 & 0.92348 & 1.00000 & & \\
D & -0.23403 & -0.00836 & -0.23289 & -0.06744 & 0.75848 & 0.88379 & 1.00000 & \\
Pol & 0.69170 & 1.00000 & 0.95875 & 0.99130 & 0.25117 & 0.22460 & -0.00873 & 0.00000 \\
\hline
\end{tabular}


Table 5. Correlation matrix between biological activity, non-conventional physicochemical parameters, and indicator parameters

\begin{tabular}{llllllllll} 
& $\log 1 / \mathrm{C}$ & $\mathrm{HE}$ & $\mathrm{ASA}$ & $\mathrm{SAG}$ & $\mathrm{I}_{2}$ & $\mathrm{I}_{\mathrm{AC}}$ & $\mathrm{I}_{\mathrm{TC}}$ & $\mathrm{I}_{\mathrm{SP}}$ & $\mathrm{I}_{\mathrm{OH}}$ \\
\hline $\log 1 / \mathrm{C}$ & 1.00000 & & & & & & & & \\
$\mathrm{HE}$ & 0.60344 & 1.0000 & & & & & & & \\
$\mathrm{ASA}$ & 0.22076 & 0.12464 & 1.0000 & & & & & & \\
$\mathrm{SAG}$ & 0.55132 & 0.18804 & 0.80707 & 1.0000 & & & & & \\
$\mathrm{I}_{2}$ & 0.37068 & 0.20317 & 0.34720 & 0.28776 & 1.0000 & & & & \\
$\mathrm{I}_{\mathrm{AC}}$ & 0.54361 & -0.05347 & 0.00696 & 0.48695 & -0.2000 & 0.0000 & & & \\
$\mathrm{I}_{\mathrm{TC}}$ & 0.48057 & 0.08232 & -0.13400 & 0.42306 & 0.05547 & 0.72111 & 1.0000 & & \\
$\mathrm{I}_{\mathrm{SP}}$ & 0.25992 & 0.16153 & 0.46235 & 0.31290 & 0.54233 & -0.10847 & -0.15041 & 1.0000 & \\
$\mathrm{I}_{\mathrm{OH}}$ & -0.53838 & -0.87471 & -0.15124 & -0.22914 & -0.10847 & -0.10847 & -0.15041 & -0.05882 & 1.0000 \\
\hline
\end{tabular}

At this stage it is worthwhile to comment on the molar refraction (MR). Since it is a combined parameter it is in essence an adjustable molecular volume and thus it equals the molar polarizability. Since molar refraction (MR) to a large extent is a measure of volume, and is also expressed in terms of the refractive index and density, it may measure the contribution due to size and shape of organic compounds acting as drugs.

For the further investigation of the effect of structural and chemical behavior on the cytotoxic concentrations of these HEPT derivatives we tested the bi- and tri- parametric combinations. In the bi-parametric correlation the results are encouraging and the good correlation coefficient is shown by the combination of $\mathrm{MR}$ and indicator parameter $\mathrm{I}_{\mathrm{OH}}$, model obtained from above combination is shown below:

$\log 1 / \mathrm{C}=0.0254( \pm 0.0067) \mathrm{MR}-0.6485( \pm 0.2747) \mathrm{I}_{\mathrm{OH}}+1.7422$

$\mathrm{n}=18, \mathrm{Se}=0.267, \mathrm{R}=0.785, \mathrm{R}^{2}=0.616, \mathrm{~F}=12.030, \mathrm{Q}=2.94$

Eq. (5) confirms the role of MR in modeling of cytotoxic concentration; this equation also demonstrates the inhibitory nature of $\mathrm{OH}$ substitution on HEPT derivatives for cytotoxic concentration. However, the best bi-parametric correlation obtained from the combination of non-conventional parameter $\mathrm{HE}$ and indicator parameter $\mathrm{I}_{\mathrm{TC}}$. The model obtained from this combination is shown below:-

$\log 1 / \mathrm{C}=0.1234( \pm 0.0277) \mathrm{HE}+0.5744( \pm 0.1416) \mathrm{I}_{\mathrm{TC}}+4.5159$

$\mathrm{n}=18, \mathrm{Se}=0.224, \mathrm{R}=0.835, \mathrm{R}^{2}=0.697, \mathrm{~F}=17.230, \mathrm{Q}=3.73$

The above model also exhibits the same role of HE in modeling $\log 1 / \mathrm{C}$ as eq. (4), this model also demonstrate the enhancement in the numerical value of $\log 1 / \mathrm{C}$ with the presence of cyclic structure on the terminal of the chain present at the $\mathrm{Z}$ position in HEPT derivatives. 
Comparison of both eq. (5) and (6) shows that, the magnitude of HE in the combinations is higher, for modeling of $\log 1 / \mathrm{C}$. In case of indicator parameters $\mathrm{I}_{\mathrm{TC}}$ shows the higher magnitude than the $\mathrm{I}_{\mathrm{OH}}$.

In case of a trivariate correlation, the results are encouraging and significant statistics are obtained from various combinations, but the best correlation is given by the combination of nonconventional physicochemical parameter $\mathrm{HE}$, indicator parameters $\mathrm{I}_{\mathrm{TC}}$ and $\mathrm{I}_{2}$. The mathematical model obtained from above variables is:

$\log 1 / \mathrm{C}=0.1089( \pm 0.0216) \mathrm{HE}+0.3851( \pm 0.1124) \mathrm{I}_{2}+0.6474( \pm 0.1102) \mathrm{I}_{\mathrm{TC}}+4.3619$

$\mathrm{n}=18, \mathrm{Se}=0.171, \mathrm{R}=0.914, \mathrm{R}^{2}=0.835, \mathrm{~F}=23.628, \mathrm{Q}=5.35$

Eq. (7) also confirms our previous results. This also exhibits the positive role of substitution at $2^{\text {nd }}$ position in the increase of numerical value of cytotoxicity of HEPT derivatives while the similar effect is also demonstrate by the presence of cyclic structure at the terminal of the chain at the $Z$ position. The study of the magnitude of both $I_{2}$ and $I_{T C}$ expresses the dominance of the presence of the cyclic structure $\left(\mathrm{I}_{\mathrm{TC}}\right)$ over the substitution at the $2^{\text {nd }}$ position $\left(\mathrm{I}_{2}\right)$. In order to confirm our finding we have estimated the $\log 1 / \mathrm{C}$ values from the best suited model and compared them with the observed values. Both the observed and calculated biological activities are presented in Table 6, and such a correlation is presented graphically in Figure 2.

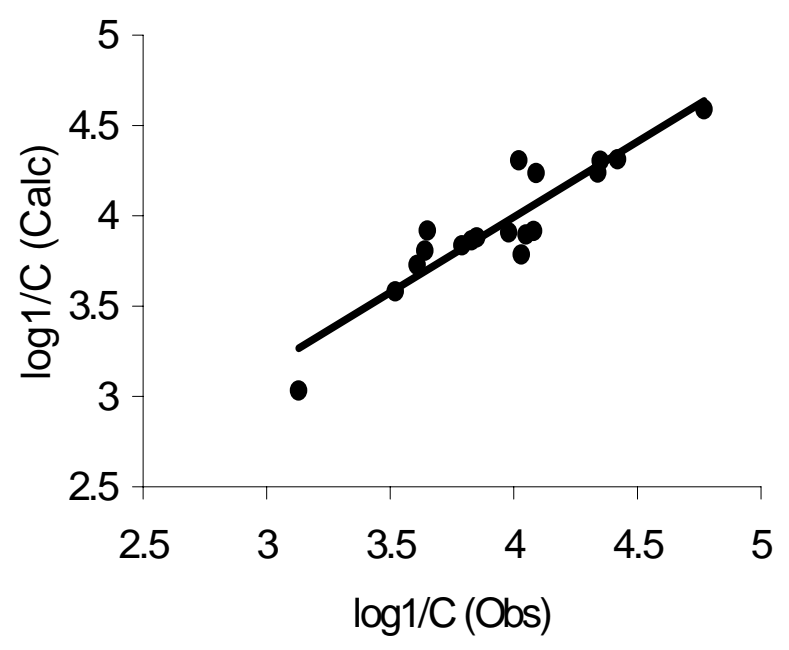

Figure 2. Graph obtained between Obs. and Calculated $\log 1 / \mathrm{C}$ values from Eq. (7). 
Table 6. Observed and calculated values of $\log 1 / \mathrm{C}$ for the HEPT derivatives used in the present study

\begin{tabular}{llll}
\hline Compd. No & $\log 1 / \mathrm{C}($ Obs. $)$ & $\log 1 / \mathrm{C}(\mathrm{Calc})$. & Residue \\
\hline 1. & 3.52 & 3.58 & -0.06 \\
2. & 3.61 & 3.73 & -0.12 \\
3. & 3.64 & 3.81 & -0.17 \\
4. & 3.83 & 3.86 & -0.03 \\
5. & 4.08 & 3.92 & 0.16 \\
6. & 4.02 & 4.31 & -0.29 \\
7. & 4.09 & 4.24 & -0.15 \\
8. & 4.35 & 4.30 & 0.05 \\
9. & 4.34 & 4.24 & 0.10 \\
10. & 3.79 & 3.84 & -0.05 \\
11. & 3.85 & 3.88 & -0.03 \\
12. & 4.77 & 4.59 & 0.18 \\
13. & 4.42 & 4.31 & 0.11 \\
14. & 3.98 & 3.91 & 0.07 \\
15. & 3.65 & 3.92 & -0.27 \\
16. & 4.03 & 3.78 & 0.24 \\
17. & 4.05 & 3.90 & 0.15 \\
18. & 3.13 & 3.03 & 0.10 \\
\hline
\end{tabular}

Based on the magnitude of residue we have selected compounds 1, 4, 8, 10, and 11 for further molecular modeling. This we have done to find out which HEPT derivative has the highest correlative and predictive potential. We have, therefore, attempted molecular modeling using Hyperchem7 software ${ }^{32}$ applying the $\mathrm{MM}+$ force field. The molecular modeling is demonstrated in Figures 3 to 7, respectively, for compounds 1, 4, 8, 10, and 11. The corresponding molecular modeling parameters are given in Table 7. In order to resolve our problem of selecting out the HEPT derivative with the best correlation potential; we have carried out further regression analysis using each of the molecular modeling parameters from Table 7. The results of regression analysis are shown in Table 8 . The model with the best correlation is shown below.

$\log 1 / \mathrm{C}=1.2609( \pm 0.6545) \mathrm{DpM}-0.0707$

$\mathrm{n}=5, \mathrm{Se}=0.232, \mathrm{R}=0.744, \mathrm{~F}=3.712, \mathrm{Q}=3.21$

Using this model (Eq. 8) we have calculated and compared the $\log 1 / \mathrm{C}$ values and observed that the residue is the least for the derivative containing $\mathrm{R}-\mathrm{H}, \mathrm{Y}-\mathrm{Me}, \mathrm{X}-\mathrm{O}, \mathrm{Z}-\mathrm{CH}_{2} \mathrm{OCH}_{2} \mathrm{CH}_{2} \mathrm{OMe}$. This is, therefore, the potential HEPT derivative for modeling the cytotoxicity of HEPT derivatives. 


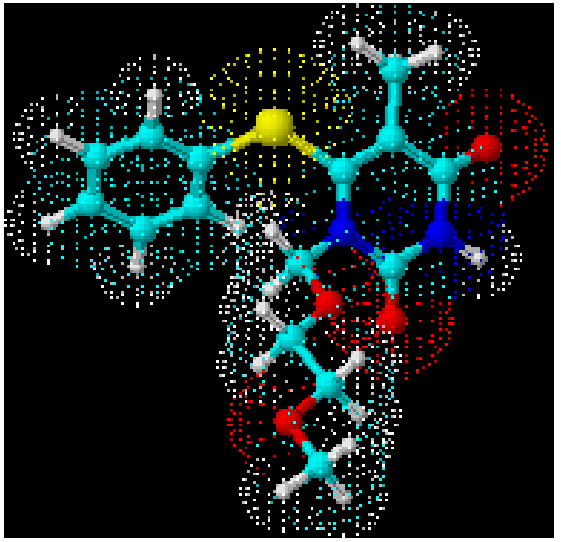

Figure 3. Optimized structure of Compound 1.

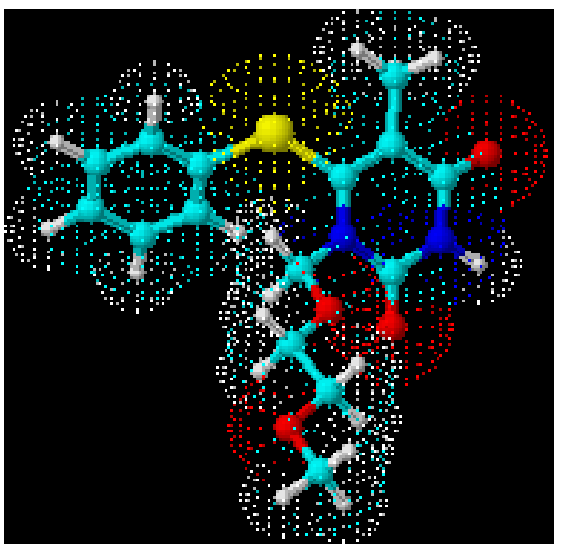

Figure 4. Optimized. structure of Compound 4.

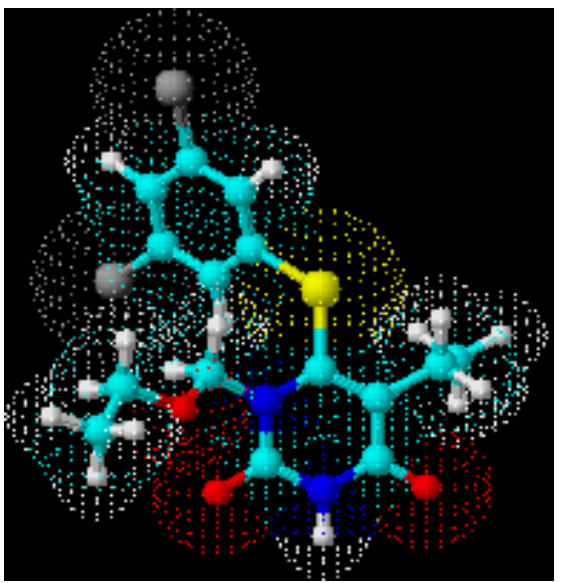

Figure 5. Optimized structure of Compound 8. 


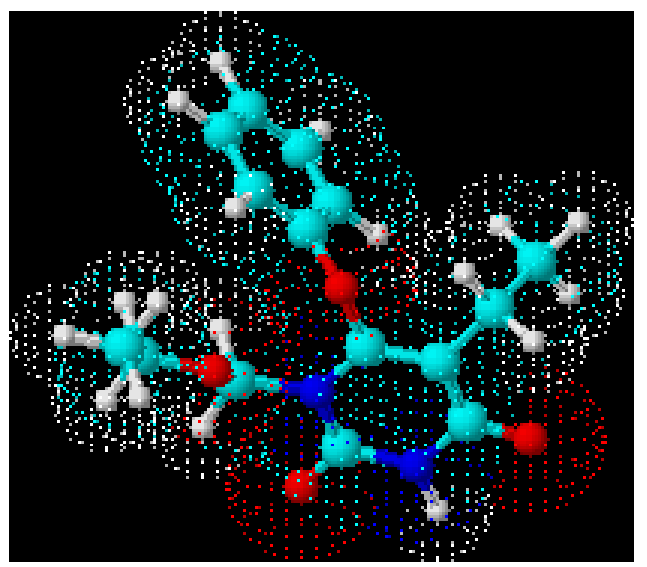

Figure 6. Optimized structure of Compound 10.

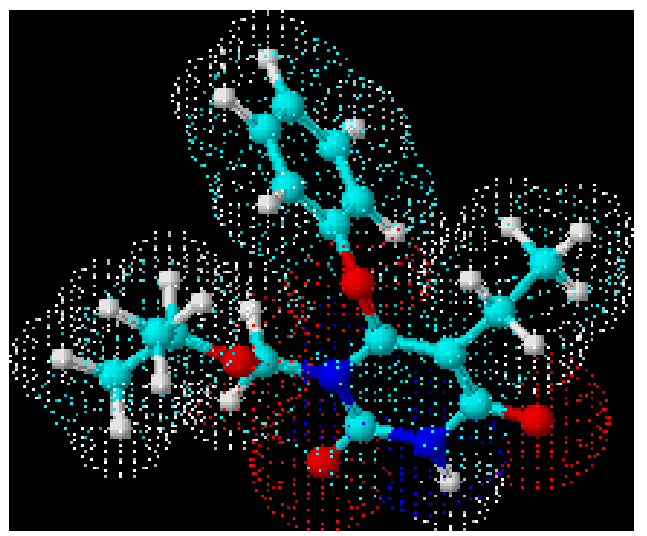

Figure 7. Optimized structure of Compound 11.

Table 7. Molecular modeling parameters for compounds having minimum residue

\begin{tabular}{clll}
\hline Compd. No. & TE & DpM & RMSg \\
\hline 1. & 11.13781 & 2.864 & 0.08749 \\
4. & 9.8394 & 3.276 & 1.053 \\
8. & 11.698 & 3.263 & 0.6207 \\
10. & 4.018 & 3.021 & 1.274 \\
11. & 5.982 & 3.195 & 0.3575 \\
\hline
\end{tabular}

$\mathrm{TE}=$ Total Energy, DpM = Dipole Moment, $\mathrm{RMSg}=$ Root Mean Square Gradient

Table 8. Correlation results from molecular modeling parameters

\begin{tabular}{lllllll}
\hline Sr. No. & $\mathrm{n}$ & Parameter & $\mathrm{Se}$ & $\mathrm{R}$ & $\mathrm{R}^{2}$ & $\mathrm{~F}$ \\
\hline 1. & 5 & $\mathrm{TE}$ & 0.3370 & 0.2189 & 0.0571 & 0.182 \\
2. & 5 & DpM & 0.2320 & 0.7436 & 0.5530 & 3.712 \\
3. & 5 & RMSg & 0.3393 & 0.2097 & 0.044 & 0.138 \\
\hline
\end{tabular}




\section{Conclusions}

From the results and discussion made above we conclude that the non-conventional physicochemical parameters can be used successfully for modeling inhibition of NNRTs and that for the present set of HEPT derivatives hydration energy (HE) is find to be prominent. Also, that this parameter (HE) yields statistically significant models upon combination with other dame descriptors.

The results also indicate that combination of QSAR/QPAR and molecular (3D) modeling can be used for select the compound with potential activity.

\section{Experimental Section}

Activity. The biological activity cytotoxic concentration $(\log 1 / \mathrm{C})$ values of the HEPT derivatives were taken from the literature. ${ }^{30}$

Physicochemical parameters. The Molar volume (MV), Parachor (Pc), Molar Refractivity (MR), Refractive Index ( $\eta$ ), Surface Tension (ST), Density (D) and Polarizability ( $\alpha$ ), for the set of benzene sulfonamide were calculated from ACD Lab software ${ }^{33}$ and the non-conventional physicochemical parameters Approximate Surface area (ASA), Surface area grid and Hydration Energies (HE) were calculated using Hyperchem7 demo-version. ${ }^{32}$ Molecular modeling parameters were calculated by applying the MM+ force field (Molecular mechanics) using Hyperchem7 demo-version. ${ }^{32}$

Indicator parameters. The indicator parameters are the dummy parameters sometimes used for accounting those structural features not covered in any molecular descriptor used. They assumed only two values 1 or 0 . If the assumed structural feature is present; then the indicator parameters are 1 otherwise it is 0 . The details of such parameters, used in the present study are given in the Result and Discussion section (Table 3)

Statistical analysis. The maximum $\mathrm{R}^{2}$ method together with stepwise regression ${ }^{31}$ was carried out for arriving at statistically significant models. In the present study, linear mathematical models are developed to study quantitative structure/property- activity relationship (QSAR). Multiple linear regression analysis is used to develop these models. (Q). ${ }^{34,35}$

The predictive potentials of these models are discussed on the basis of quality factor

\section{Acknowledgements}

The authors' thanks are due to Padmakar V Khadikar for his excellent guidance in performing this study. 


\section{References}

1. Randic', M. Topological Indices. In Encyclopedia of Computational Chemistry; Schleyer, P. v. R., Allinger, N. L., Clark, T., Gasteiger, J., Kollman, P. A., Schaefer, H. F., III., Schreiner, P. R., Eds.; John Wiley \& Sons: Chichester, 1998.

2. Hansch, C.; Kurup, A.; Garg, R.; Gao, H.; Chem. Rev. 2001, 101, 619.

3. Luco, J. M.; Ferretti, F. H., J. Chem. Inf. Comput. Sci. 1997, 37, 392.

4. Tronchet, J. M. J.; Grigorov, M.; Dolatshahi, N.; Moriaud, F.; Weber, J. Eur. J. Med. Chem. 1997, 32, 279.

5. Lawtrakul, L.; Hannongbua, S. Sci. Pharm. 1999, 67, 43.

6. Jalali-Heravi, M.; Parastar, F., J. Chem. Inf. Comput. Sci. 2000, 40, 147.

7. Klein, C. T.; Lawtrakul, L.; Hannongbua, S.; Wolschann, P., Sci. Pharm. 2000, 68, 25.

8. Lawtrakul, L.; Hannongbua, S.; Beyer, A.; Wolschann, P. Biol. Chem. 1999, 380, 265.

9. Lawtrakul, L.; Hannongbua, S.; Beyer, A.; Wolschann, P. Monatsh. Chem. 1999, 130, 1347.

10. Tanaka, H.; Takashima, H.; Ubasawa, M.; Sekiya, K.; Nitta, I.; Baba, M.; Shigeta, S.; Walker, R. T.; De Clercq, E.; Miyasaka, T., J. Med. Chem. 1992, 35, 337.

11. De Clercq, E. Clin. Microbiol. Rev. 1995, 8, 200.

12. Young, S. D. Perspect. Drug Discov. Des. 1993, 1, 181.

13. De Clercq, E. J. Med. Chem. 1995, 38, 249.

14. Esnouf, R.; Re, J.; Ross, C.; Jones, Y.; Stammers, D.; Stuart, D. Struct. Biol. 1995, 2, 303.

15. Thakur, M.; Thakur, A.; Khadikar, P.V.; Supuran, C.T., Bioorg. Med. Chem. Lett. 2005, 15, $1,203$.

16. Thakur, A.; Arkivoc 2005, (xiv), 49.

17. Thakur, A.; Thakur, M.; Vishwakarma, S., Bioorg. Med. Chem. 2004, 12, 5, 1209.

18. Thakur, M.; Thakur, A.; and Khadikar, P. V. Bioorg. Med. Chem. 2004, 12, 9, 2287.

19. Thakur, A.; Thakur, M.; Kakani, N.; Joshi, A.; Gupta, A. ARKIVOC 2004, (xiv),1,36.

20. Thakur, A; Thakur, M. Res. J. Chem. Environ. 2003, 7, 1, 51.

21. Thakur, A; Thakur; M. Bioinformatics India 2003, 1, 1, 63.

22. Thakur, A. Ult. Scie. Phy. Scie. 2003, 15, 2, 209.

23. Thakur, A.; Thakur, M.; Khadikar, P. V. Bioorg. Med. Chem. 2003, 11, 23, 5203.

24. Douali, L.; Villemin, D.; Zyad, A.; Cherqaoui, D. Molec. Diver. 2004, 8, 1, 1.

25. Gayen, S.; Debnath, B.; Samanta, S.; Jha, T. Bioorg. Med. Chem. 2004, 12, 6, 1493.

26. Solov'ev, V. P.; Varnek, A. J. Chem. Inf. Comput. Sci. 2003, 43, 5, 1703.

27. Chen, H. F.; Yao, X. J.; Li, Q.; Yuan, S. G.; Panaye, A.; Doucet, J. P.; Fan, B. T. SAR \& QSAR Environ. Res. 2003, 14, 5-6, 455.

28. Douali, L.; Villemin, D.; Cherqaoui, D. J. Chem. Inf. Comput. Sci. 2003, 43, 4, 1200.

29. Bazoui, H.; Zahouily, M.; Zakarya, D.; Sebti, S.; Boulajaaj, S., Phys. Chem. News 2002, 6,1, 135.

30. Rajni G.; Satya, P.; Gupta, H. G.; Mekapati S. B.; Asim, K. D.; Hansch, C. Chem. Rev. 1999, 99, 3525. 
31. Chaterjee, S.; Hadi, A.S.; Price, B. Regression Analysis by Examples, $3^{\text {rd }}$ Edn. Wiley VCH: New York, 2000.

32. HyperChem 7 Demoversion from WWW.Hyperchem.com

33. ACD-Lab software for calculating the referred physicochemical parameters; Chemsketh S.O, WWW. Acdlabs.com

34. Pogliani, L. Amino Acids 1994, 6, 141.

35. Pogliani, L. J. Phys. Chem. 1996, 100, 18065. 